\title{
Epistemology in African Thought: Theory and Language
}

\author{
Bruno Yammeluan Ikuli ${ }^{1} \quad$ Ukanga Lambert Peter ${ }^{1,2}$ \\ 1.Institute of Foundation Studies, Federal University, Otueke, Yenagoa, Nigeria \\ 2.Department of Philosophy, University of Nigeria, Nsukka, Nigeria
}

\begin{abstract}
This work presents epistemology in African thought system as it is informed by theory and language. Numerous problems faced in Africa on how we know what we know and the power of sustaining knowledge becomes clearer as we define knowledge in the question of ontology and metaphysics. The African nations have been termed as not been able to produce written historical documents until recent times. This thought seems to downgrade African theory of knowledge even with it deep seated languages of meaning. To foster an understanding of African theory of knowledge, we employ African epistemology in theory and in language which informed ontology and metaphysics. This work utilizes primary and secondary sources while deploying any useful materials and journals articles on African theory of knowledge, language, ontology and metaphysics. This study linked up the African theory of knowledge with historical search that connect African thought system as we found that African epistemology lies in and beneath the statuesque of African though system. We conclude that in the context of Africa epistemology in theory and language, each culture have a philosophical position that are articulated by its gifted individuals in any given society.
\end{abstract}

Keywords: Epistemology, Theory, Knowledge, Language, Africa, Ontology, Metaphysics

DOI: $10.7176 / J L L L / 69-04$

Publication date:June 30th 2020

\subsection{INTRODUCTION}

Epistemology has to do with the study of the theory of knowledge. The inquisition of epistemology is: what is knowledge? What does it mean to Know? These questions imply many other questions such as: How is knowledge acquired? What, if anything, do the senses contributing to knowledge? What does reason contribute? For some philosophers, the field of metaphysics and epistemology are, in a way, the pillars of all the rest. Why would one say this? Are the question: What is real? Would those questions not determine your whole philosophical outlook? Therefore in an attempt to answer these and similar questions pertaining to epistemology, we present epistemological thought in African theory and it language. The traditional African avoids the fatty and rich fare of speculative metaphysics; but sticks to the lane and unadulterated data of experience. (Aja 2015). In the language theory of epistemology in African thought system, the wise or the sage within the community thought. For that reason, science is look at as only able to describe patterns of phenomena.

Indeed, the reality that lies beneath the phenomena contains the traditional African metaphysics, explained in the language of African thought system and cannot be scientifically comprehended. The implication of this methodological principle vis-à-vis those of Western epistemologist, become very clear as one gradually proceed in terms of the idea established by Locke, Berkeley, Hume, and Kant.

\subsection{African Theory of Knowledge in Thought and Language}

The basic problem of knowledge in African thought system is there by ascertaining whether or not what are claimed as knowledge are actually knowledge rather than just mistaken opinion using various African proverbial and idiomatic expressions that carries the people choices of word. (Kusua 2014). Does what African claim as knowledge really reveal reality? In our day to day sojourn on earth mistakes are often made in matters of perception and inference. For instance, in the dark, the long rope forgotten by any household appears to $\mathrm{b}$ a snake; a flower in front of a house appear to be a man with a gun hiding to lunge an attack. These could cause someone to commit a very serious crime. But if there were only rope, for example, on the path obviously no one could have knowledge of a snake on the path. As example of this are considered it becomes possible to speculate that perhaps what appears to us is always different from what really is. It might seem that the eye always present things are red, blue and pink while in the actual sense they are yellow, black and orange. The ear equally presents sound different from what they really sound are. These therefore distort the reality with which they come in contact leading to skeptical consideration of this kind and therefore pushing the traditional African to try analyzing what knowledge really is. In African philosophy, we analyze knowledge using the idea of the subject, the object to known and how the object can be known or the mean of coming to know the object. (Aja 2015). In line with this (Usie 2016) added that, these issues of subject object are base on what to be known in African thought system rest upon a singular idea of the language in used for communication purposes. We refer to this relationship as knowledge situation. It has been discovered that the analysis of claim in knowledge rest upon four factors in ascertaining when someone knows something. (Aja 2015). The one who knows is the subject. The something that is being known is the object. The 
whole idea of coming to know thing is to conquer ignorance; in other words, separating the subject is separated from the objects; as they come to relates in certain ways. This relationship informs knowing the object.

\subsection{Means of knowledge}

In line with African thought, knowledge is all about revealing the object and the mean of this knowledge are distinguished according to how the object was reveal to the knower. This code of distinction capitulate perception, inference, analogy, and testimony as the four basic means of the sources of knowledge. (Aja 2015). One distinguished this knowledge by doing four basic different thing and coming to know something in each of them in different ways.

\subsubsection{Knowledge of perception}

By this, we mean that form of knowledge as true and established that arises from the contact one made with senses with their proper object. If one were to mistakenly see a rope to be a snake, we do not see it to be a genuine perception because it would not stand for a true knowledge because there was no snake there to perceive.

Indeed, following Hermann von Helmholtz, (Gregory 1997) who illustrate visual perceptions as comatose assumption from sensory data and knowledge taken from the past? Perceptions he said are regarded as similar to projecting hypotheses of science, but are psychologically probable into external space and acknowledged as our mainly immediate reality. (Gregory 1997). The question that may be raise here is how a particular judgment can be known to be true? Apparently, it is not possible to test directly the corresponding between the perception and the reality being perceived, for this will mean knowing what true knowledge is by moving out of knowledge itself. To know something outside the umbrella of a particular knowledge is not possible according to African theory of knowledge which derives from African metaphysics. (Aja 2015, Makere 2016).

Consequently, the African put forward that knowledge that are mistaken in their claims are detected, ultimately, in terms of how successful their practice are. Indeed, expanding this principle of verification of perception claims the position is reached that whatever works-in the sense that it provides for successful activity, and eventually, human happiness and liberation- is true because it is seen to correspond to reality as attested by a successful activity. In this direction, African philosophers and scholars define true perception in terms of correspondence to reality. But the usually advocate pragmatism as the means of testing this correspondence. In addition, the Africans acknowledge extra-ordinary perception.

\subsubsection{Knowledge from Inference}

Though perception is a basic kind of knowledge recognized by African thought system, but there are still other three which one of them is knowledge from inference. Knowledge from inference is independence kind of knowledge that produces knowledge that suffices after other knowledge. (Aja 2015). Again (Markolo 2018), added that, inference kind of knowledge at times comes from an already existing knowledge be it intentional or by accident or perceptional in a way. Examples, from perceptional knowledge one can infer any kind of knowledge. That is to say, inference is proceeding from perceived knowledge. Indeed, the African differentiate amid way of thinking to convince one-self and way of thinking to convince the other.

\subsubsection{Knowledge from Comparison}

Furthermore, African also recon with comparison as knowledge that is based on their similarities and their differences; for instance, if one have a prior knowledge of a goat, and was meant to understand that a sheep was like a goat in certain ways, he will then understand that the animal he met on his way was sheep. Based on this, (Mfon 2013) posits that comparison form of knowledge only emerge from the visual that is already written in the brain. It is usually occur with an object that is known and the one that is unknown. Here the Africans have this conception that similarities are objective and perceivable. (Aja 2015). Although comparative knowledge involves perception and inference, it cannot be abridged to either of them, and as a result, it is to be counted as a third means of knowledge.

\subsubsection{Testimony}

In the line-up of African theory of knowledge, the fourth means of valid kind of knowledge is testimony. It could mean in the literally sense the word of a person or knowledge achieved as a result of something told by a dependable foundation. (Kuslam 2017). Opinion is not knowledge, because such can contain an error, but knowledge cannot.

Thus, any form of simple hearing an opinion of another person is not a means of knowledge contents in African thought system, but when the knowledge claim of another are heard, there come a genuine knowledge attained, if and only if the claim is understood. To solidify a testimonial kind of knowledge, three basic criteria are posited:

1. There must be honesty and reliability in respect with ones speech.

2. The speaker must truly know what he /she is speaking.

3. The receiver or the hearer must understand precisely what he/she is hearing. (Aja 2015).

Thus, we can say that African theory of reality or metaphysics follows suit from African metaphysics or ontology. Knowledge and wisdom entails how the world of forces could be understood based on their interactions. 
True wisdom and knowledge therefore lies in the ontological understanding of how the world of forces and what inhabit it looks like in the universe of many things, their hierarchy, their cohesion and interaction.

In line with the forgoing, Tempels' accord God in African context as a force, as a wisdom that inhabit all forces. (Tempels 1959 ), one is said to know in African thought system if approaching the divine wisdom. One approaches the divine wisdom in African context the older they get. In that hierarchical structure is that ancestors have mores wisdom, followed by the elders the dead and the living. But in that mundane level of wisdom, man remains the only force that without him all other forces are frozen. (Tempels 1959, Jahn 1961).

Furthermore, the African tried in distinguishing between practical intelligence and habitual intelligence. For instance, practical intelligence is cleverness, slyness, in dealing with dependent aspect of forces why habitual intelligence is active knowledge of the nature of forces and their relationship. This kind of knowledge, for African is different from knowledge from book.

The pertinent question goes thus: How does African justify their beliefs? What basic assumption governs those beliefs? How does African claim to know? What logic does the mind follow to conclude in that order of knowledge? If the Africans have their own belief in reality and knowledge, I think this must be the work of human experience.

\subsection{African Knowledge Situation of Logic, Theory and Language as a Source and Scope of Human Knowledge}

In line with African theory of knowledge, there is no self detachment in dealing with knowledge about human experience, as demanded by scientific knowledge. Before truth is been known about personal experience, a person must put himself in that condition. Going by this, (Ekpe 2004) put it that when one say I know how you feel is always a sympathetic testimony to loves ones because you cannot know how a person feels when the situation is not applicable to you. African epistemology therefore does not distinguish between the ego and the world. (Aja 2015), while African theory of knowledge makes the self the centre of the world. (Aja 2015). Indeed, every reality in African world is personal experience because it centres on the self because it employs the totality of man and his faculty in play.

Therefore truth in Africa has to be an existential truth which is lived and felt and not from presumption, (Iwang 2016) as there is a great link between self experience and experiencing self. Indeed, the togetherness of the ego and world emerges from the mental attitude that is very different from the conception of the West. The African world is then more unitary as compared to the analytic concept of the Western world as everything in African is filled with life forces. The African experience in this context is an uncreated experience by the African; instead it comes from their natural form of divinity. Thus, this informs that religion in African thought system arises from the divine giver himself and that reality is then experience from such arrival. This therefore informs African world to have life in everything that exist.

More so, African forms of knowledge have not really brought fact into play, but a complicated act of judgment that involves factors and theories. For African, a tree is a life force interacting with another life force. With this, an African man using his intuition grasps the relationship between the hierarchies of forces.

Deep-seated to an indispensable knowledge, western epistemology in line with Aristotle's three laws:

1. Law of Identity- Any entity whatever is what it is and is not something else.

2. Law of non contradiction-No entity whatever can be both what it is and what it is not with the same specification."A rose cannot be not a rose."

3. Law of excluded middle- Any entity whatever is either what it is or it is not; (eg.) a thing is either a rose or it is not a rose. (Aja 2015). This therefore presupposed a thought of anyone in anything wherever they are. Indeed, the African therefore followed logic that is paradoxical as three laws of thought do not necessary applies to all reality. Therefore, for African, a thing can be and with the same design be said not to be. We are and we are not, in everything, there is every other thing.

Indeed, since African world is centered on the self, the African world is more personal as they lived in their culture. African world is therefore created from human experience. It is a world of dependency in an African thought system, theory, logic language, perception, ideas and knowledge. It is a world that possess it own language and it is from that language that African epistemology if form in line with African thought system. African therefore eliminates the errors of rationality and naturalism using cultural and unitary form of reality as it denies any static point or view of world history. The epistemological view point therefore is now based on the dynamism embedded in the traditional African theory and reality, hence ontology or African metaphysics.

Regrettably, lack of written document in African thought system rendered gifted men in traditional African thought system untraceable. In the context of African theory of Knowledge, there are no Descartes, Humes, Kant, etc. that there are no such name dose not removed the fact that there were no epistemologist of the past, the African equivalent of Socrates, Spinoza, Leibniz, Berkerly, Locke, Hume and Kant.

We conclude by saying that in the context of Africa epistemological thought system in theory and language, each culture have a philosophical position that are articulated by its gifted individuals in any given society. The 
sage in traditional African thought system still posses such wisdom to articulate knowledge using the language of converging deep seated ideologies that informs the life and the reality of the people.

\section{References}

Aja, Egbeke. (2015) Doing African Philosophy, Nsukka: University of Nigeria Nsukka Press.

Ekpe, Bassey. (2004) Language of Epistemology in African Thought system, Calabar: Unical Press.

Gregory, L. Richard. (1997) Knowledge in perception and illusion From: Phil. Trans. R. Soc. Lond. B 352, 11211128 Department of Psychology, University of Bristol, 8 Woodland Road, Bristol BS8 1TA UK

Iwang, Donatus, (2016). Epistemology in Annang: Concept and Theories. Lagos: Ikoyi Bamba Publication. Jahn, Jahneinz. (1961) Muntu. New York: Dover.

Kusua, Mbebrie. (2014). The Think tank to African Theory Knowledge, Uyo: Ndimadi Press.

Makere, Oluyfemei. (2016). Knowledge, Thought and Perspective, Lagos: Oluyiera publication Ltd.

Markolo, Uyime. (2018). Thinking Africa, It Origin and Theories, Ikot Ekpene: Uyanga Press. Ltd.

Mfon, Udoudoma. (2013). Ideas and Ideologies, Origin and Concept. Calabar: Effiom Presss.

Tempels, Placid. (1959) Bantu Philosophy, Trans. A. Rubbens. Paris: Presence Africaine.

Usie, Kudiaka. (2016). Knowledge and it Origin a Perspective of Thought, Memphe: Caminie Press Ltd. 